OPEN ACCESS

Edited by:

Maria Pappas,

Democritus University of Thrace,

Greece

Reviewed by:

Dominiek Vangansbeke,

Biobest, Belgium

Yong Liu,

Hunan Academy of Agricultural

Sciences (CAAS), China

Panagiotis Milonas,

Benaki Phytopathological Institute,

Greece

*Correspondence:

Teresa Vaello

mtv11@alu.ua.es

Specialty section:

This article was submitted to Agroecology and Ecosystem Services,

a section of the journal

Frontiers in Ecology and Evolution

Received: 04 September 2018 Accepted: 31 December 2018

Published: 21 January 2019

Citation

Vaello T, Pineda A and Marcos-García MÁ (2019) Role of Thrips Omnivory and Their Aggregation Pheromone on

Multitrophic Interactions Between

Sweet Pepper Plants, Aphids, and

Hoverflies. Front. Ecol. Evol. 6:240.

doi: 10.3389/fevo.2018.00240

\section{Role of Thrips Omnivory and Their Aggregation Pheromone on Multitrophic Interactions Between Sweet Pepper Plants, Aphids, and Hoverflies}

\author{
Teresa Vaello ${ }^{1 *}$, Ana Pineda ${ }^{2}$ and $M^{a}$ Ángeles Marcos-García ${ }^{1}$ \\ 1 Instituto Universitario de Investigación, Centro Iberoamericano de la Biodiversidad, Universidad de Alicante, Alicante, Spain, \\ ${ }^{2}$ Department of Terrestrial Ecology, Netherlands Institute of Ecology (NIOO-KNAW), Wageningen, Netherlands
}

In complex food webs, plants are commonly attacked by multiple herbivorous species, affecting the preference and performance of other herbivores and natural enemies. The role of omnivorous insects in ecosystems may be more complex because of the consumption of both plant and animal organisms. However, the effect of omnivorous insects on herbivores and natural enemies, has received little attention so far. The main goal of this study was to investigate whether the dual herbivore interaction between aphids and thrips, an omnivorous pest, on a sweet pepper system, may affect different trophic levels, from plant and aphid performance until the third trophic level, i.e., preference and performance of the predatory hoverfly Sphaerophoria rueppellii. Additionally, we tested whether the aggregation pheromone of the thrips Frankliniella occidentalis, could disturb the oviposition behavior of the predatory hoverfly. Our results show that the presence of thrips decreases host plant and aphid performance. Furthermore, despite not affecting syrphid larval performance, thrips presence reduces fecundity of the adults that emerge from those larvae. Additionally, we observed that syrphids avoid ovipositing on plants with either thrips or thrips aggregation pheromone. The present study reveals how the presence of thrips or a semiochemical compound related to thrips, can impact the behavior and performance of an aphidophagous predator.

Keywords: dual attack, Frankliniella occidentalis, Myzus persicae, Sphaerophoria rueppellii, omnivore-herbivore interaction, pheromone

\section{INTRODUCTION}

In nature, plants are commonly attacked by multiple herbivorous species. Plant responses to feeding by single herbivores can impact the preference and performance of other herbivores (Stam et al., 2014; Pineda et al., 2017; Vaello et al., 2018), affecting the attractiveness and performance of natural enemies (Shiojiri et al., 2002; Ponzio et al., 2014; Stam et al., 2017). Many of multi-attack interactions include omnivorous arthropods which are capable of exploiting both plant and prey resources, ensuring their survival in the absence of one resource (Coll and Guershon, 2002). Thus, in dual attack situations, herbivores that co-exist with omnivores on the same plant compete for 
plant food but also have a potential risk of omnivore predation. For example, negative performance and preference where observed in the herbivore whitefly Trialeurodes vaporariorum (Westwood 1856) (Hemiptera: Aleyrodidae) in co-occurring system with the omnivorous thrips Frankliniella occidentalis Pergande 1895 (Thysanoptera; Thripidae) (Pappas et al., 2018). Moreover, these omnivore-herbivore interactions may cascade up to other trophic levels. For example, thrips control by Amblyseius swirskii (Athias-Henriot 1962) (Acari: Phytoseiidae) was delayed in the presence of the whitefly $T$. vaporariorum, whereas the control of this whitefly was improved in the presence of thrips (Messelink and Janssen, 2008; Messelink et al., 2010).

Most of the studies about the responses of predators to dual herbivory are mainly focused on the behavior of predatory mites (De Boer et al., 2008; Zhang et al., 2009; Lima et al., 2017) or predatory bugs (Moayeri et al., 2007), whereas predator performance, and effects of omnivorous arthropods, have received little attention so far. Predatory hoverflies (Diptera: Syrphidae) are important aphid natural enemies, which are often studied in the context of biological control (Brewer and Elliott, 2004; Pineda and Marcos-García, 2008; Almohamad et al., 2009; Amorós-Jiménez et al., 2014, 2015; Amiri-Jami et al., 2017), being commercially used as biological control agents in greenhouse crops. Gravid syrphid females, searching for plants on which they lay eggs, are able to detect and avoid potential intraor interspecific competition (Hindayana et al., 2001; Fréchette et al., 2007; Pineda et al., 2007; Amorós-Jiménez et al., 2015). Thus, oviposition behavior is the first step in a successful biological control program, especially for natural enemies with larval stages much less mobile than the adult stage, such as the case of hoverflies. Although a previous study demonstrated syrphid's vulnerability to predation by other generalist predators (Fréchette et al., 2007), to our knowledge no information is available about syrphid behavior, under dual herbivore attack.

In sweet pepper crops, but also in many other crops worldwide, the phloem feeder aphid Myzus persicae (Sulzer 1776) (Hemiptera: Aphididae) and the thrips F. occidentalis often cooccur on a same plant (Messelink et al., 2013). Thrips usually feed on leaf tissue or plant pollen, but may also feed from eggs of predatory mites (Faraji et al., 2002; Janssen et al., 2003), eggs of spider mites (Agrawal and Klein, 2000) or crawlers of the whitefly Trialeurodes vaporariorum (Westwood 1856) (Hemiptera: Aleyrodidae) (van Maanen et al., 2012). Nowadays, aphids are a major problem in biological control programs on sweet pepper (Bloemhard and Ramakers, 2008), and thrips have been described to disturb and even prey on aphid predators and other natural enemies (Magalhães et al., 2005; Messelink et al., 2013). The predatory hoverfly Sphaerophoria rueppellii (Wiedemann 1830) (Diptera: Syrphidae) is commonly released in greenhouse crops to control, among other aphid species, the green peach aphid M. persicae (Amorós-Jiménez et al., 2012, 2015), however the potential disruption of syrphids through thrips presence is not known.

Thus, in this study, we investigated how the interaction between aphids and omnivorous thrips may affect different trophic levels, from plant and aphid performance to the third trophic level, assessing preference and performance of a predatory hoverfly. Previous studies have shown that dual herbivory by insects belonging to different feeding guilds can affect plant performance (Ponzio et al., 2016), and how through plant-mediated interactions, the performance of future herbivores feeding on those plants can be decreased (Erb et al., 2011; Pappas et al., 2018). Based on those studies, we hypothesize that in presence of $F$. occidentalis (omnivorous and plant cell-content feeder), sweet pepper growth and aphid (plant phloem feeder) performance will be negatively affected. Regarding the effects of thrips presence on syrphids, we expect a reduced number of eggs oviposited on plants with dual herbivory compared with only aphids presence, and associated to this, a negative syrphid performance. This hypothesis is based on previous studies where $F$. occidentalis preyed on eggs from its natural enemy Iphiseius degenerans (Berlese 1889) (Acari: Phytoseiidae) (Faraji et al., 2002; Janssen et al., 2003) and also where non-prey insects such as ants were able to reduce the performance and oviposition of the hoverfly Episyrphus balteatus (de Geer 1776) (Diptera: Syrphidae) (AmiriJami et al., 2017). Moreover, we expected that the aggregation pheromone of F. occidentalis [(R)-lavandulyl acetate: neryl (S)-2methylbutanoate], could be used by $S$. rueppellii to discriminate between plants with or without thrips. This hypothesis is based on our previous results showing that the thrips aggregation pheromone was attractive to a thrips natural enemy, the predatory bug Orius laevigatus (Fieber 1860) (Hemiptera: Anthocoridae) (Vaello et al., 2017).

\section{MATERIALS AND METHODS}

\section{Plants and Insects}

The study system consisted of sweet pepper (Capsicum annuum L., var. California wonder), a cultivar commonly used in greenhouse crops, the aphid $M$. persicae, the omnivorous thrips F. occidentalis, and the hoverfly S. rueppellii. Sweet pepper plants were grown from seeds in plastic pots $(5.5 \mathrm{~cm}$ in diameter, $7 \mathrm{~cm}$ in height) with a mix of soil and vermiculite $1: 1$, in a climatic chamber at $24^{\circ} \mathrm{C}, 60 \%$ relative humidity $(\mathrm{RH})$ and a $16 \mathrm{~h}$ light and $8 \mathrm{~h}$ dark photo regime. Insects were reared at the CIBIO, University of Alicante, Spain. M. persicae was reared on $C$. annuum plants for multiple generations and F. occidentalis was reared on fresh green beans Phaseolus vulgaris L. (Fabaceae) as described by Espinosa et al. (2002), under the same conditions as above. The predator S. rueppellii was provided by BioNostrum Pest Control S.L. (Alicante, Spain) in three different life stages: eggs, pupae and adults (10 \pm 1 day old). S. rueppellii was maintained as described by (Amorós-Jiménez et al., 2012).

\section{Performance of Sweet Pepper and Myzus persicae}

Aphid population growth was measured in the presence of single or dual herbivory. We established two treatments: (i) single herbivory: 20 sweet pepper plants (5 weeks old) were infested with 10 individuals of $M$. persicae adults ( $8 \pm 1$ days old) on the second fully expanded leaf of each plant, during 3 days (ii) dual herbivory: 20 sweet pepper plants were arranged as for the treatment of single herbivory, but 3 days before each plant was 
infested with $10 \mathrm{~F}$. occidentalis larvae (2 days old) on the second fully expanded leaf of each plant, allowing the colonization and feeding on the plant. All the plants were individually enclosed in plastic cages with two windows with anti-thrips gauze to prevent the escape of insects and ensure ventilation. Twice a week, the location of the cages with plants was randomized, to minimize positional effects. After 7 days of infestation, the total number of $M$. persicae individuals was counted in both treatments. Plant height was measured before and after infestation, and above and belowground biomass was collected at the end of the experiment and oven dried $\left(40 \hat{\mathrm{A}}^{\circ} \mathrm{C}\right.$ during 5 days) before measuring dry weight.

\section{Performance of Sphaerophoria rueppellii}

To assess the performance of $S$. rueppellii, we used the same treatments as explained above in a new experiment. After 3 days of aphid infestation in single herbivory and dual herbivory (and after 6 days of thrips infestation in dual herbivory treatment), three $S$. rueppellii larvae (2 days old since eggs hatched) were transferred to each of the infested plants with a fine paint brush. In total 120 larvae were used $(20$ plants $\times 2$ treatments $\times 3$ larvae per plant). Larval development was monitored daily, and larval mass was recorded on the second instar (L2), third instar (L3), and pupal stage. Newly emerged adults were kept in a net cage $(60 \times 60 \times 30 \mathrm{~cm})$ separately for each treatment. Adults were provided with water, sucrose, multi-flower bee pollen, and an aphid-infested pepper plant as oviposition stimulus to allow ovaries maturation. Then 9 days old S. rueppellii females were allowed to lay eggs individually for $48 \mathrm{~h}$ in cages $(60 \times 60 \times$ $30 \mathrm{~cm}$ ) with an aphid-infested sweet pepper plant (infested with 10 individuals of $M$. persicae adults ( $8 \pm 1$ days old) on the second expanded leaf, during 3 days). The number of females used were: 21 for the treatment with aphids and 17 for the treatment with aphids and thrips. Fertility was measured by counting the number of eggs laid by females 24 and $48 \mathrm{~h}$ after release. A new aphid-infested plant was offered after $24 \mathrm{~h}$. Fecundity was measured counting the hatched first instar (L1) larvae 2 days after syrphid oviposition. After the oviposition assay, wing length was determined for males and females separately as a surrogate for total body size in syrphids and as a good indicator for adult fitness (Stubbs and Falck, 1983; Kingsolver and Huey, 2008; Amorós-Jiménez et al., 2014). Morphological measurements were always done using the left wing, to avoid any effect due to asymmetry. We used an Image Analyzer LEIKA (M205C/DFC425, Cambridge, United Kingdom) for wing length measurements. All the bioassays were performed in climate chamber at $24^{\circ} \mathrm{C}, 60 \%$ relative humidity $(\mathrm{RH})$ and a $16 \mathrm{~h}$ light and $8 \mathrm{~h}$ dark photo regime.

\section{Oviposition Preference of S. rueppellii}

Oviposition preference was determined in a two-choice experiment. An insect-proof cage $(30 \times 30 \times 60 \mathrm{~cm})$ was placed inside a climatic chamber. Two sweet pepper plants $(5$ weeks old) were placed in two different corners of the cage to test the oviposition preference for plants infested with single (aphids) or dual herbivory (aphids and thrips). Plant position was randomized for every new replicate. To study the oviposition response, a total number of 60 individuals of syrphid females (9 days old), obtained from pupae from BioNostrum Pest Control S.L., were tested. The number of eggs after 2 and $24 \mathrm{~h}$ were recorded individually per female syrphid. The oviposition preference bioassay was performed in climate chamber at $24^{\circ} \mathrm{C}$, $60 \%$ relative humidity $(\mathrm{RH})$ and a $16 \mathrm{~h}$ light and $8 \mathrm{~h}$ dark photo regime.

In a new experiment we tested the syrphid oviposition response to single herbivore (aphids) vs. a component of $F$. occidentalis aggregation pheromone (R)-lavandulyl acetate:neryl (S)-2-methylbutanoate [RLA:NMB] (Hamilton et al., 2005). RLA and NMB were synthesized according to Hamilton et al. (2005) and Zada and Harel (2004), respectively. The purity of the compounds was analyzed by gas chromatography-mass spectrometry (GC-MS) integration, and the optical purity was estimated from the corresponding specifications of the starting materials (RLA 99.2\% purity, 98.7\% enantiomeric excess (ee) and NMB $91.5 \%$ purity, $98.0 \%$ ee). In order to prepare the odor source, tested compounds were individually diluted $(1: 1$, $\mathrm{v} / \mathrm{v}$ ) in paraffin oil (Sigma-Aldrich, USA). The ratio used in this experiment was selected according to previous results testing the attraction of the natural enemy $O$. laevigatus to $F$. occidentalis aggregation pheromone (Vaello et al., 2017). Parafilm oil (2 $\mu \mathrm{l})$ (used as control) and 1RLA:2.3NMB blend $(2 \mu \mathrm{l})$ were applied on a piece of filter paper $(1 \times 1 \mathrm{~cm})$ that was placed on the second expanded leaf of the sweet pepper plant. After $15 \mathrm{~min}$, the female adults were released (the filter paper was kept in the plant during all the oviposition experiment). The treatments used in this case were: (i) Aphid treatment: 10 M. persicae ( $8 \pm 1$ days old) were placed on the second fully expanded leaf from each sweet pepper plant, and after 3 days we added $2 \mu \mathrm{l}$ of paraffin oil on the plant, as described above, (ii) Aphid-pheromone treatment: $10 M$. persicae ( $8 \pm 1$ days old) were placed on the second fully expanded leaf from each sweet pepper plant, and after 3 days we added to the plant $2 \mu$ l of 1 RLA: $2.3 \mathrm{NMB}$ ratio from F. occidentalis aggregation pheromone. The oviposition cage consisted of an insect-proof cage $(30 \times 30 \times 60 \mathrm{~cm})$ which was placed in a climatic chamber. A total number of 84 syrphid female individuals ( 9 days old obtained from BioNostrum Pest Control S.L.) were tested in this experiment. The parameters used to study ovipositional response were: number of eggs laid at 2 and $24 \mathrm{~h}$ after syrphid release. The oviposition preference bioassay was performed at $24^{\circ} \mathrm{C}, 60 \%$ relative humidity (RH) and a $16 \mathrm{~h} \mathrm{light}$ and $8 \mathrm{~h}$ dark photo regime.

\section{Thrips Predation}

To assess how herbivores can affect predator performance, potential predation on syrphid eggs by omnivore thrips was recorded in two experiments. In the first experiment we observed the predation and/or damaged eggs with a Petri dish bioassay of two treatments: (i) Aphid treatment: 10 aphids ( \pm \pm 1 days old) were placed in a sweet pepper leaf with 10-15 syrphid eggs in a Petri dish and (ii) Aphid and thrips treatment: 10 aphids ( $8 \pm$ 1 days old) and 10 second instar thrips larvae ( $3 \pm 1$ days old) were placed on a sweet pepper leaf with 10-15 syrphid eggs in a Petri dish. Syrphid eggs were obtained by confining 15-20 mature females in an insect-proof cage $(30 \times 30 \times 60 \mathrm{~cm})$ with aphid 

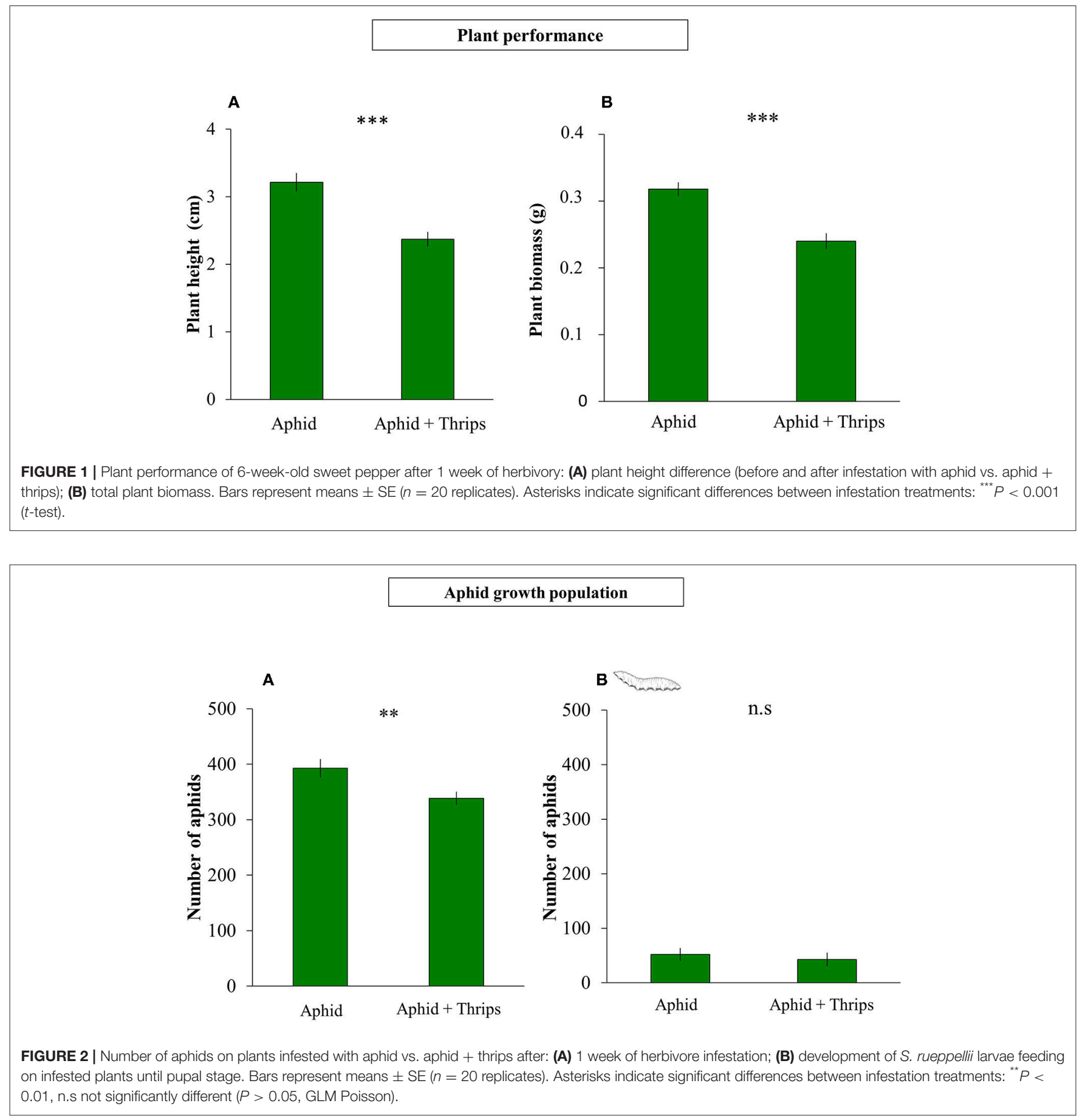

infested sweet pepper plants as stimulus; after $2 \mathrm{~h}$ we selected leaves with syrphid eggs for the experiment and aphids were removed carefully with a paint brush. After $24 \mathrm{~h}$ of introducing aphids and thrips in the Petri dish, eggs were observed under a binocular microscope, to record egg damage, and after $48 \mathrm{~h}$, survival rate was followed in time to observe egg hatching.

A second experiment was conducted with entire sweet pepper plants ( 5 weeks old). Each treatment included 20 sweet pepper plants that were infested with 10 individuals of $M$. persicae adults ( $8 \pm 1$ days old) on the second fully expanded leaf of each plant for 3 days. All the plants were individually enclosed in plastic cages with two windows with anti-thrips gauze to prevent the escape of insects and ensure ventilation. Afterwards, one adult female of S. rueppellii was allowed to oviposit for $24 \mathrm{~h}$ on each plant. Eggs were counted and we left on the plant a number of 10-15 eggs (to standardize the numbers of eggs per plant). 
From the results of the Petri dish experiment, we selected two treatments with different thrips life stages, with the aim to assess the effect of thrips life stage on predation behavior: (i) Larval treatment: 10 second instar thrips were transferred on the plant with a fine paint brush. (ii) Adult treatment: 10 adults (15 \pm 1 days old) were released on the plant with a fine paint brush. Egg damage, hatching and larval survival at $48 \mathrm{~h}$ were observed. Both experiments were performed in a climate chamber at $24^{\circ} \mathrm{C}$, $60 \%$ relative humidity $(\mathrm{RH})$ and a $16 \mathrm{~h}$ light and $8 \mathrm{~h}$ dark photo regime.

\section{Statistical Analyses}

Plant performance (plant height and plant biomass) was analyzed with a $t$-test. Aphid density was analyzed with Generalized Linear Models (GLM) with Poisson distribution and dispersion parameter estimated. Regarding data on syrphid performance; weight and wing length measures were analyzed with $t$-test, fecundity was analyzed using a GLM with Poisson distribution and fertility with a GLM with binomial distribution. Results from the oviposition experiment were analyzed with the Wilcoxon test. All statistical tests were performed using SPSS 15.0.; SPSS Inc., Chicago, IL, USA.

\section{RESULTS}

\section{Thrips Presence Decreases Plant Performance and Aphid Population}

Plant height was measured before and after infestation, and the height between these two time points was reduced when thrips were present in the system compared to only aphids $\left(F_{(1,38)}=1.325 ; P<0.001\right.$; Figure 1A). Similarly, plant biomass was lower when thrips and aphids were together on the same plant compared to aphids alone $\left(F_{(1,38)}=0.312 ; P<\right.$ 0.001; Figure 1B). After 7 days of herbivore infestation, the population of aphids was higher in plants without thrips $\left(F_{(1,38)}\right.$ $=7.261 ; P=0.007$; Figure 2A). We also measured plant performance when $S$. rueppellii was present. The difference in plant height between single or dual herbivory in the presence of syrphid larvae was not significant $\left(F_{(1,38)}=0.999 ; P=\right.$ $0.166)$, whereas plants had lower biomass when thrips were also present $\left(F_{(1,38)}=0.346 ; P=0.046\right)$. The population of aphids when syrphids were present after 7 day-infestation, did not show differences between single or dual herbivory $\left(F_{(1,38)}=0.339 ; P\right.$ $=0.561$; Figure 2B).

\section{Thrips Presence Decreases Fecundity but Not Fertility of S. rueppellii}

S. rueppellii larval development, was not affected by the presence of thrips in our study system. Parameters such as larval and pupal biomass, adult survival and wing length were not significantly affected by single or dual herbivory (Table 1). However, in the adults that developed from larvae feeding on an aphid colony with thrips presence, fecundity was negatively affected by thrips, with a lower number of eggs laid by female adults, both at $24 \mathrm{~h}\left(F_{(1,36)}=11.648 ; P=0.001\right)$ and $48 \mathrm{~h}\left(F_{(1,36)}=15.057\right.$; $P<0.001$; Figure 3A) after female adults release. In contrast, fertility was not affected by the presence of thrips, with similar
TABLE 1 | Morphological traits of S. rueppellii when fed on M. persicae with and without the presence of $F$. occidentalis.

\begin{tabular}{lll}
\hline Measure & Thrips absent & Thrips present \\
\hline L2 weight $(\mathrm{mg})$ & $1.342 \pm 0.081$ & $1.417 \pm 0.160$ \\
L3 weight $(\mathrm{mg})$ & $11.834 \pm 0.454$ & $11.738 \pm 0.303$ \\
Pupa weight $(\mathrm{mg})$ & $9.595 \pm 0.141$ & $10.728 \pm 1.980$ \\
Wing length males $(\mathrm{mm})$ & $3.619 \pm 0.024$ & $3.656 \pm 0.034$ \\
Wing length females $(\mathrm{mm})$ & $3.881 \pm 0.024$ & $3.843 \pm 0.041$ \\
\hline
\end{tabular}

Measures represent means $\pm S E$. Data here presented were not significantly different between the two treatments (t-test analyses).

egg hatching $\left(F_{(1,28)}=1.435 ; P=0.231\right.$; Figure 3B), nor was the mortality of the emerging first instar larvae $(\mathrm{L} 1)\left(F_{(1,28)}=0.360\right.$; $P=0.549)$.

\section{Syrphid Females Avoid Ovipositing on Plants With Thrips or Their Aggregation Pheromone}

The presence of $F$. occidentalis in an aphid colony did not affect the decision of $S$. rueppellii to lay their eggs in the first $2 \mathrm{~h}$ after syrphid release $(Z=-1.550 ; P=0.121)$. However, after $24 \mathrm{~h}$, the number of eggs recorded on plants infested with aphids and thrips was less than on plants without thrips $(Z=-3.178$; $P=0.001$; Figure 4A). In the second experiment where we tested the oviposition behavior in the presence of a synthetic infochemical of the thrips aggregation pheromone, we observed similar results. Females did not show significant differences selecting an oviposition place between plants with aphids vs. plants with aphids and thrips aggregation pheromone on the first $2 \mathrm{~h}(Z=-1.299 ; P=0.194)$. However, after $24 \mathrm{~h}$, the number of eggs on plants with aphids and thrips aggregation pheromone was lower than in plants with only aphids $(Z=-2.992 ; P=0.003$; Figure 4B).

\section{Thrips-Predator Interaction Does Not Affect Final Syrphid Survival}

In a first Petri dish assay we tested whether thrips would damage hoverfly eggs. We observed that F. occidentalis second instar larvae damage syrphid eggs, causing loss of turgor on its surface $\left(F_{(1,58)}=15.661 ; P<0.001\right.$; Figures 5A, 6), although no effect on survival rate was recorded $\left(F_{(1,58)}=1.964 ; P\right.$ $=0.161$; Figure 5B). In a second experiment, we tested if the developmental stage of thrips affects differently egg damaging in an experiment with whole plants. The results showed that adult thrips caused lower syrphid egg damage than second instar thrips larvae $\left(F_{(1,38)}=6.843 ; P=0.009\right.$; Figure 5C), and for the Petri dish experiment, this damage did not affect syrphid survival $\left(F_{(1,38)}=0.285 ; P=0.594\right.$; Figure 5D).

\section{DISCUSSION}

The present study demonstrated that the effects of the omnivorous insect F. occidentalis, in dual herbivore interaction with aphids, could scale up to the third trophic level. Thrips 


\section{Fertility and fecundity}

A

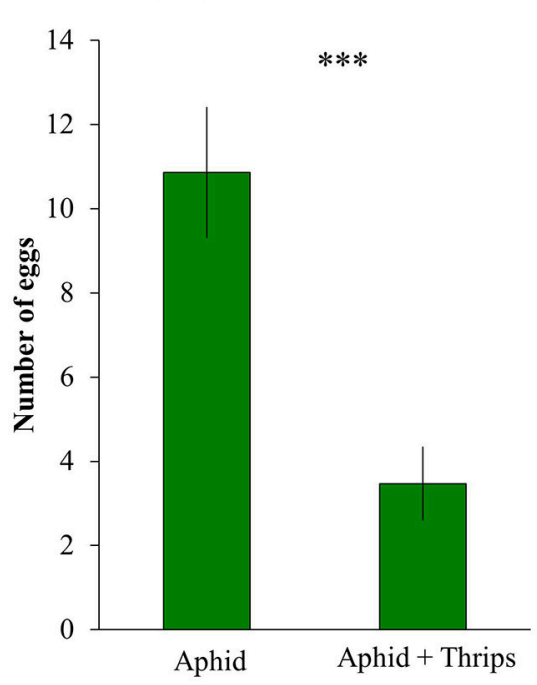

B

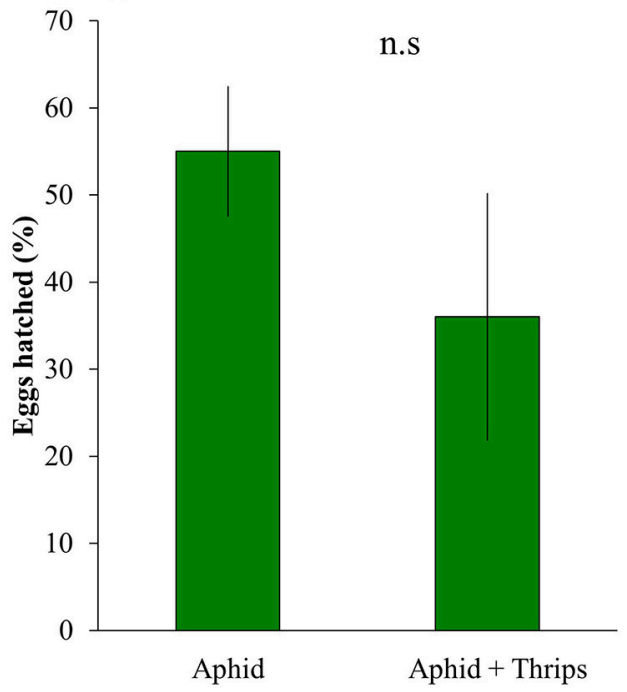

FIGURE 3 | Fecundity and fertility of S. rueppellii female adults after completing their life cicle feeding on aphid-infested plants $(n=21$ replicates) and on aphid + thrips-infested plants ( $n=17$ replicates). (A) Number of syrphid's eggs laid (Fecundity) and (B) number of viable eggs hatching (Fertility). Bars represent means \pm SE. Asterisks indicate significant differences between infestation treatments: ${ }^{* \star *} P<0.001$, n.s not significantly different $P>0.05$ (GLM).

\section{Oviposition preference}
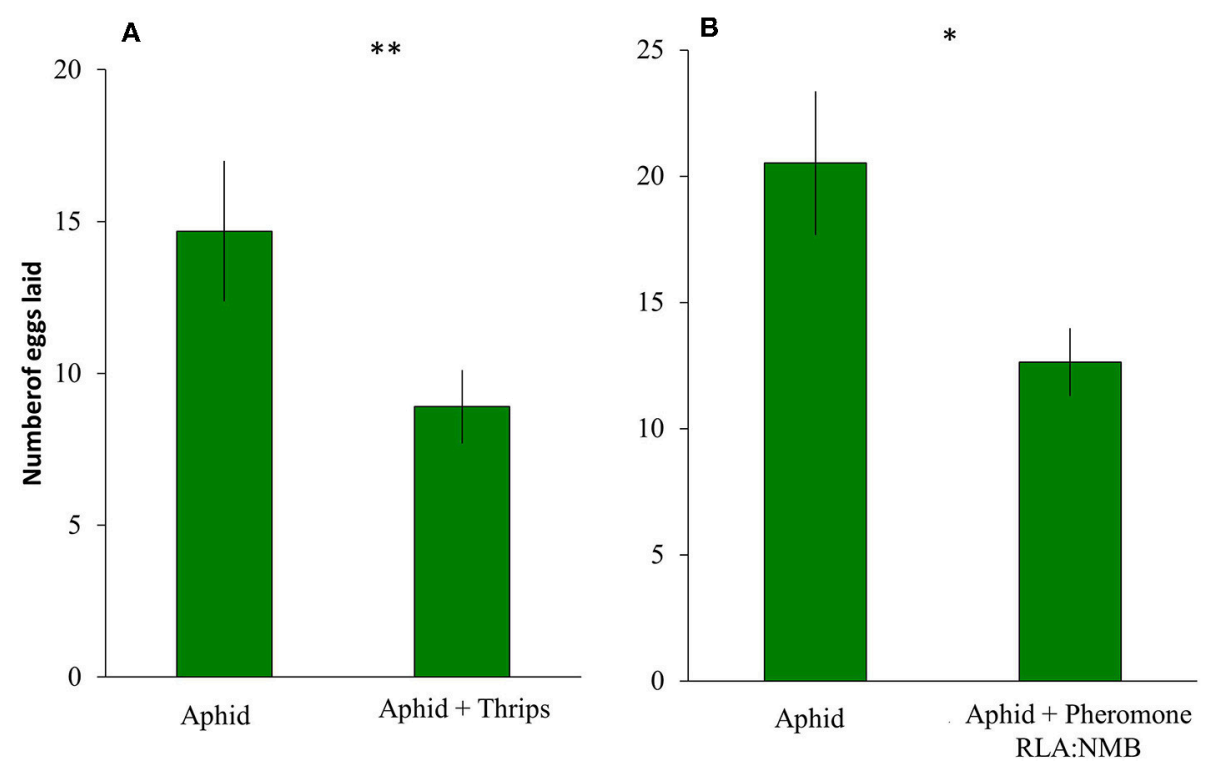

FIGURE 4 | Oviposition of S. rueppellii on sweet pepper plants after $24 \mathrm{~h}$ (A) Number of syrphid eggs laid on aphid vs. aphid+thrips-infested plants $(n=60$ replicates) and (B) number of syrphid eggs laid on aphid-infested plants vs. aphid-infested plants plus $2 \mu \mathrm{l}$ of $1 \mathrm{RLA}$ : 2.3NMB F. occidentalis aggregation pheromone $\left(n=42\right.$ replicates). Bars represent means \pm SE. Asterisks indicate significant differences between infestation treatments: ${ }^{* *} P \leq 0.001,{ }^{*} P<0.05$ (Wilcoxon test). 


\section{Thrips-syrphid interaction}
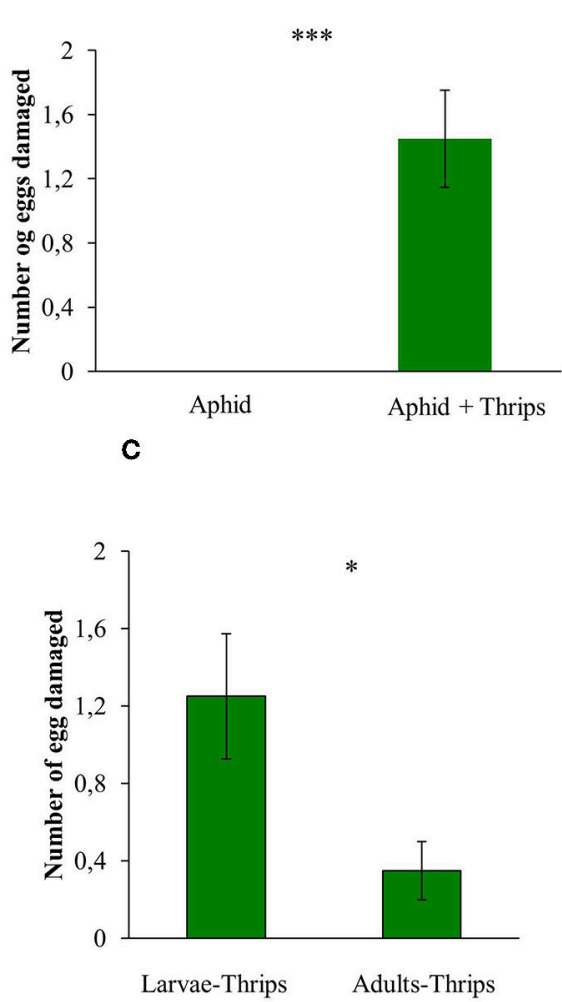

B
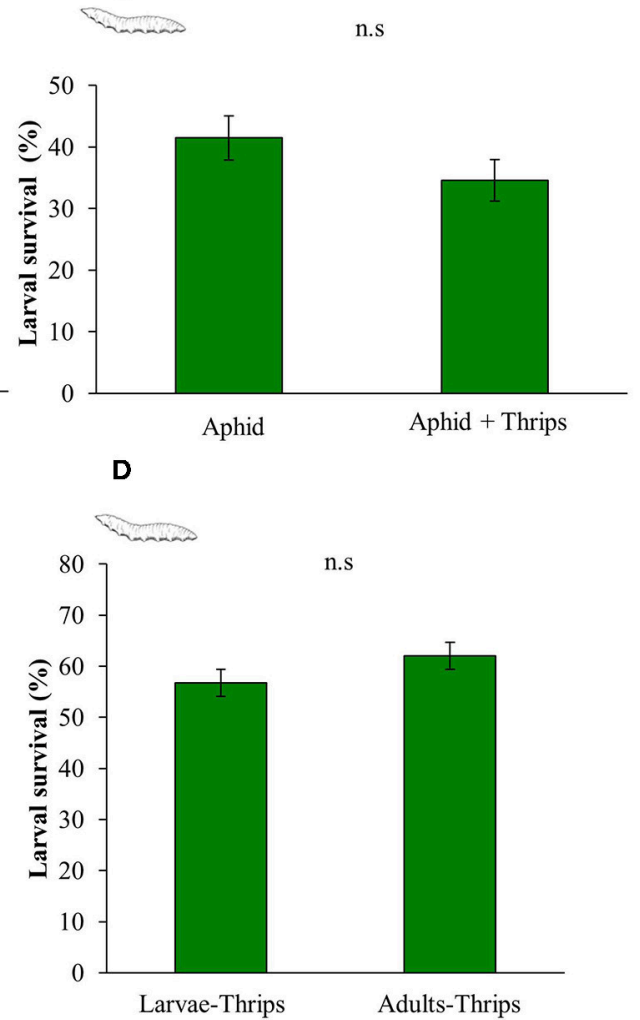

FIGURE 5 | Direct effects of the presence of thrips on syrphid performance. (A) S. rueppellii eggs damaged by prey in a Petri dish experiment; (B) S. rueppellii larval survival after prey presence in a Petri dish experiment; (C) S. rueppellii eggs damaged by larvae vs. adults thrips on entire plants and (D) S. rueppellii larval survival in the presence of second instar larvae and adults thrips on entire plants. Bars represent means $\pm S E$ ( $n=20$ replicates). Asterisks indicate significant differences between infestation treatments: ${ }^{\star \star \star} P<0.001,{ }^{\star} P<0.05$ and n.s not significant differences $(P>0.05, \mathrm{GLM})$.
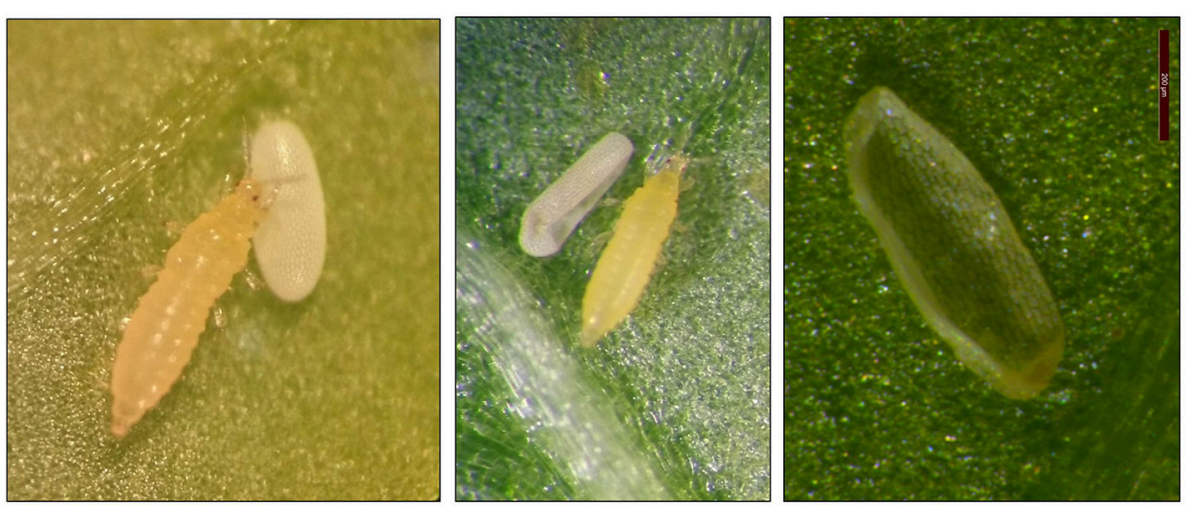

FIGURE 6 | Egg of S. rueppellii damaged by a F. occidentalis second instar larva.

affected plant growth as well as aphid population growth but also the ovipositional preference and performance of the aphidophagous hoverfly $S$. rueppellii. We also provide the first evidence of thrips predation on syrphid eggs, although without affecting syrphid juvenile survival in our study. Moreover, we showed how specific chemical cues from the aggregation pheromone of $F$. occidentalis could disrupt syrphid ovipositional behavior.

Thrips can affect plant-mediated interactions with arthropods such as spider mites or whiteflies (Pallini et al., 1998; Agrawal 
et al., 1999; Pappas et al., 2018). However, although the simultaneous presence of thrips and aphids is common in many agricultural crops, few studies have focused on their interactions. Despite that in our study the number of thrips was much lower than the number of aphids (10 thrips vs. more than 300 aphids per plant), thrips presence reduced the growth of sweet pepper plants, as it has been shown for a range of vegetable crops (Welter et al., 1990; Shipp et al., 1998). This reduction in plant performance is probably due to the induction of plant defenses by thrips in early stages of plant development (5 weeks old), producing an energetic cost associated with plant defense (Agrawal, 1998). In a previous study, we showed that the performance of $F$. occidentalis on $M$. persicae pre-infested plants was enhanced (Vaello et al., 2018). In this study, we observed the opposite direction of this interaction showing a negative effect of thrips on aphids. Hence, our results show both direct effects of thrips herbivory in sweet pepper growth (with reduced host-plant quality) and indirect effects on aphid performance (with lower aphid population).

Due to these effects on aphids, we hypothesized that the performance of the predator $S$. rueppellii could be negatively influenced by thrips presence indirectly via the reduced population of prey (aphids) in the presence of thrips. Our results show that the fecundity of $S$. rueppellii was reduced, although larval development was not affected by thrips presence. This type of effects has been shown for the hoverfly E. balteatus, whose larval survival was not different when feeding on aphids on two different plant species, in contrast to its fecundity (AmiriJami et al., 2017). Similar results were found between thrips and predatory mites, where the net reproduction of Neoseiulus californicus (McGregor 1954) (Acari: Phytoseiidae) was reduced in the presence of thrips (Choh et al., 2017). However, the fact that in the presence of $S$. rueppellii, aphid population was not affected by the presence of thrips indicates that thrips do not interfere with the hoverfly success as biological control agent.

Moreover, in this study we also demonstrate that thrips presence can have direct effects on predators. We observed that thrips larvae could damage the surface of the chorion of syrphid eggs (Figure 6), without however affecting juvenile survival. The lack of effect on survival rate may be explained by the fact that the hatching rate of $S$. rueppellii's eggs was $<60 \%$, and probably the effect of egg damage by thrips was diluted, although we still observed a trend. Probably in natural conditions with plants experiencing higher infestation of thrips, the survival rate of syrphids would be lower. Regarding the opposite direction, although thrips are a rare prey for syrphids, a previous study already reported Sphaerophoria quadrituberculata Bezzi, 1915 (Diptera: Syrphidae) feeding on thrips Cercothrips afer Priesner, 1925 (Thysanoptera: Phlaeothripidae) (Callan, 1955). In previous assays we observed that $<10 \%$ of S. rueppellii larvae were able to feed and complete their life cycle until adulthood, feeding exclusively on thrips (Marcos-García, pers. comm.). These findings suggest that syrphids developing in co-occurrence conditions predate preferably on aphids but they could occasionally also consume non-preferred prey such as thrips (Figure 7). Feeding on a non-optimal prey may decrease predator performance, as occurred with the predator

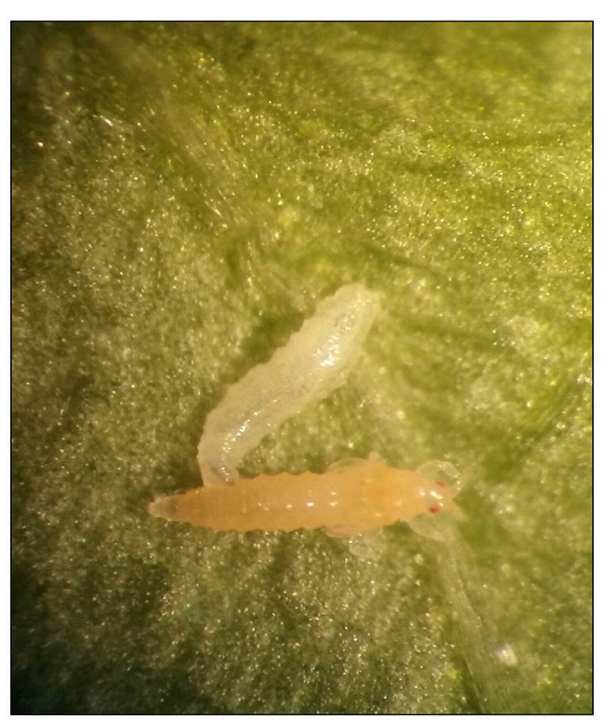

FIGURE 7 | First instar of S. rueppellii larva feeding on F. occidentalis second instar larva.

N. californicus in the presence of thrips (Choh et al., 2017). One possibility is therefore that syrphid larvae feed with thrips to protect themselves, but this behavior needs to be further tested.

Moreover, we suggest that another direct effect of thrips on hoverflies could be related to causing stress on their larvae with a later effect on fecundity. In a recent study, the presence of ants in aphid colonies reduced the performance and oviposition of E. balteatus through disturbing syrphid predation or with ants preying on syrphid larvae (Amiri-Jami et al., 2017). In a similar way, here we observed reduced oviposition in aphidinfested plants with thrips presence, and a reduced performance associated to that behavior. Hoverflies show an oviposition preference for plant-aphid species combinations that maximize their performance, either avoiding heterospecific competitors (Almohamad et al., 2009), intraguild interactions (Pineda et al., 2007), or a risk to their offspring (Almohamad et al., 2009). The "intimidation" by omnivorous herbivores to predators may induce the ecology of fear (Clinchy et al., 2013), triggering stress to predators, decreasing the number of eggs laid and preventing optimal oviposition searching.

Syrphids exploit various chemical blends from plants and insects when searching for oviposition sites, such as the semiochemical (E)- $\beta$-farnesene $(\mathrm{E} \beta \mathrm{F})$, the main component of the alarm pheromone of most aphid species (Francis et al., 2005; Verheggen et al., 2008). However, limited information exists about syrphids response to semiochemicals from nonpreferred prey. Our results show that the aggregation pheromone of F. occidentalis leads to oviposition avoidance by S. rueppellii, indicating that predators are able not only to rely on semiochemicals from a non-preferred prey, but also using it to distinguish unsuitable oviposition places. Although not evaluated in the current study, one possibility is that syrphid females retain their eggs in the absence of suitable oviposition sites, 
as occurred for Eupeodes corollae (Fabricius. 1794) (Diptera: Syrphidae) in the absence of aphids (Almohamad et al., 2009). In contrast, the predatory bug $O$. laevigatus, a natural enemy of $F$. occidentalis, responded positively to the aggregation pheromone of its prey (Vaello et al., 2017). Thus, the aggregation pheromone RLA:NMB seems to act both as an attractant for a thrips predator such as $O$. laevigatus and as repellent for $S$. rueppellii. Moreover, the fact that $S$. rueppellii prefers to oviposit on plants without thrips, could be due to the detection of fewer aphids in colonies with thrips presence as we observed. Further possibilities to be tested are whether S. rueppellii avoids competition or intraguild predation with other predators with this behavior (such as O. laevigatus), or how the presence of thrips may alter the volatile blend produced by plants infested with aphids, affecting in the end the oviposition behavior of syrphids.

In conclusion, this study shows that although the presence of omnivorous insects can affect three trophic levels, the efficiency of the biological control may not be compromised, as was shown for S. rueppellii that controlled the aphid population in both the presence and the absence of thrips. This study also raised awareness about how an aggregation insect pheromone may act as a repellent for natural enemies. Hence, in a biological control context, it

\section{REFERENCES}

Agrawal, A. A. (1998). Induced responses to herbivory and increased plant performance. Science 279, 1201-1202. doi: 10.1126/science.279.5354.1201

Agrawal, A. A., and Klein, C. N. (2000). What omnivores eat: direct effects of induced plant resistance on herbivores and indirect consequences for diet selection by omnivores. J. Anim. Ecol. 69, 525-535. doi: 10.1046/j.1365-2656.2000.00416.x

Agrawal, A. A., Kobayashi, C., and Thaler, J. S. (1999). Influence of prey availability and induced host-plant resistance on omnivory by western flower thrips. Ecology 80, 518-523.

Almohamad, R., Verheggen, F. J., and Haubruge, É. (2009). Searching and oviposition behavior of aphidophagous hoverflies (Diptera: Syrphidae): a review. Biotechnol. Agron. Soc. 13, 467-481.

Amiri-Jami, A. R., Sadeghi-Namaghi, H., and Gilbert, F. (2017). Performance of a predatory hoverfly feeding on Myzus persicae (Hem. Aphididae) reared on two brassicaceous plants varies with ant attendance. Biol. Control. 105, 49-55. doi: 10.1016/j.biocontrol.2016.11.011

Amorós-Jiménez, R., Pineda, A., Fereres, A., and Marcos-García, M. A. (2012). Prey availability and abiotic requirements of immature stages of the aphid predator Sphaerophoria rueppellii. Biol. Control 63, 17-24. doi: 10.1016/j.biocontrol.2012.06.001

Amorós-Jiménez, R., Pineda, A., Fereres, A., and Marcos-García, M. A. (2014). Feeding preferences of the aphidophagous hoverfly Sphaerophoria rueppellii affect the performance of its offspring. BioControl 59, 427-435. doi: 10.1007/s10526-014-9577-8

Amorós-Jiménez, R., Robert, C. A. M., Marcos-García, M. A., Fereres, A., and Turlings, T. C. J. (2015). A differential role of volatiles from conspecific and heterospecific competitors in the selection of oviposition sites by the aphidophagous hoverfly Sphaerophoria rueppellii. J. Chem. Ecol. 41, 493-500. doi: 10.1007/s10886-015-0583-9

Bloemhard, C. M. J., and Ramakers, P. M. J. (2008). Strategies for aphid control in organically grown sweet pepper in the Netherlands. IOBC/WPRS 32, 25-28.

Brewer, M. J., and Elliott, N. C. (2004). Biological control of cereal aphids in North America and mediating effects of host plant and habitat manipulations. Annu. Rev. Entomol. 49, 219-242. doi: 10.1146/annurev.ento.49.061802.123149 is crucial to analyse the effect of co-occurring pest species interactions to predict the effectiveness of natural enemies, especially for oviposition site selection and subsequent predator performance.

\section{AUTHOR CONTRIBUTIONS}

TV, AP, and MÁM-G conceived and designed the research. TV conducted the experiments. TV and AP analyzed the data. $\mathrm{TV}, \mathrm{AP}$, and MÁM-G interpreted the results and wrote the manuscript. All authors contributed critically to the drafts and gave final approval for publication.

\section{FUNDING}

This work was supported by Spanish Ministry of Science, Innovation and Universities (CGL2016-79054).

\section{ACKNOWLEDGMENTS}

The authors thank BioNostrum Pest Control S.L for providing experimental syrphid material. This research is part of the Teresa Vaello $\mathrm{PhD}$ studies, at CIBIO Research Institute of the University of Alicante, Spain.
Callan, E. McC. (1955). Larvae of Sphaerophoria as predators on thrips in South Africa. Nature 175:345. doi: 10.1038/175345a0

Choh, Y., Sabelis, M. W., and Janssen, A. (2017). Predatory interactions between prey affect patch selection by predators. Behav. Ecol. Soci Biol. 71:66. doi: 10.1007/s00265-017-2288-2

Clinchy, M., Sheriff, M. J., and Zanette, L. Y. (2013). Predator-induced stress and the ecology of fear. Funct. Ecol. 27, 56-65. doi: 10.1111/1365-2435.12007

Coll, M., and Guershon, M. (2002). Omnivory in terrestrial arthropods: Mixing plant and prey diets. Annu. Rev. Entomol. 47, 267-297. doi: 10.1146/annurev.ento.47.091201.145209

De Boer, J. G., Hordijk, C. A., Posthumus, M. A., and Dicke, M. (2008). Prey and non-prey arthropods sharing a host plant: effects on induced volatile emission and predator attraction. J. Chem. Ecol. 34, 281-290. doi: 10.1007/s10886-007-9405-Z

Erb, M., Robert, C. A., Hibbard, B. E., and Turlings, T. C. (2011). Sequence of arrival determines plant-mediated interactions between herbivores. J. Ecol. 99, 7-15. doi: 10.1111/j.1365-2745.2010.01757.x

Espinosa, P. J., Fuentes, J. F., Contreras, J., Bielza, P., and Lacasa, P. (2002). Método de cría en masa de Frankliniella occidentalis (Pergande). Bol. San. Veg. Plagas, 28, 385-390.

Faraji, F., Janssen, A., and Sabelis, M. W. (2002). Oviposition patterns in a predatory mite reduce the risk of egg predation caused by prey. Ecol. Entomol. 27, 660-664. doi: 10.1046/j.1365-2311.2002.00456.x

Francis, F., Martin, T., Lognay, G., and Haubruge, E. (2005). Role of (E)- $\beta$ farnesene in systematic aphid prey location by Episyrphus balteatus larvae (Diptera: Syrphidae). Eur. J. Entomol. 102, 431-436. doi: 10.14411/eje.2005.061

Fréchette, B., Rojo, S., Alomar, O., and Lucas, É. (2007). Intraguild predation between syrphids and mirids: who is the prey? Who is the predator? BioControl 52,175-191. doi: 10.1007/s10526-006-9028-2

Hamilton, J. G., Hall, D. R., and Kirk, W. D. (2005). Identification of a maleproduced aggregation pheromone in the western flower thrips Frankliniella occidentalis. J. Chem. Ecol. 31, 1369-1379. doi: 10.1007/s10886-005-1351-z

Hindayana, D., Meyhofer, R., Scholz, D., and Poehling, H. M. (2001). Intraguild predation among the hoverfly Episyrphus balteatus deGeer (Diptera: Syrphidae) and other aphidophagous predators. Biol. Control 20, 236-246. doi: 10.1006/bcon.2000.0895 
Janssen, A., Willemse, E., and Van Der Hammen, T. (2003). Poor host plant quality causes omnivore to consume predator eggs. J. Anim. Ecol. 72, 478-483. doi: 10.1046/j.1365-2656.2003.00717.x

Kingsolver, J. G., and Huey, R. B. (2008). Size, temperature, and fitness: three rules. Evol. Ecol. Res. 10, 251-268.

Lima, D. B., Oliveira, H. K. V., Melo, J. W. S., Gondim Jr, M. G. C., Sabelis, M., Pallini, A., et al. (2017). Predator performance is impaired by the presence of a second prey species. Bull. Entomol. Res. 107, 313-321. doi: $10.1017 /$ S0007485316000900

Magalhães, S., Tudorache, C., Montserrat, M., van Maanen, R., Sabelis, M. W. and Janssen, A. (2005). Diet of intraguild predators affects antipredator behavior in intraguild prey. Behav. Ecol. 16, 364-370. doi: 10.1093/beheco/arh171

Messelink, G. J., Bloemhard, C. M. J., Sabelis, M. W., and Janssen, A. (2013). Biological control of aphids in the presence of thrips and their enemies. Biocontrol 58, 45-55. doi: 10.1007/s10526-012-9462-2

Messelink, G. J., and Janssen, A. (2008). Do whiteflies help controlling thrips? IOBC/wprs Bull. 32, 131-134.

Messelink, G. J., van Maanen, R., van Holstein-Saj, R., Sabelis, M. W., and Janssen, A. (2010). Pest species diversity enhances control of spider mites and whitefies by a generalist phytoseiid predator. BioControl 55, 387-398. doi: 10.1007/s10526-009-9258-1

Moayeri, H. R. S., Ashouri, A., Poll, L., and Enkegaard, A. (2007). Olfactory response of a predatory mirid to herbivore induced plant volatiles : multiple herbivory vs. single herbivory. J. Appl. Entomol. 131, 326-332. doi: 10.1111/j.1439-0418.2007.01177.x

Pallini, A., Janssen, A., and Sabelis, M. W. (1998). Predators induced interspecific competition for food in refuge space. Ecol. Lett. 1, 171-177.

Pappas, M. L., Tavlaki, G., Triantafyllou, A., and Broufas, G. (2018). Omnivoreherbivore interactions: thrips and whiteflies compete via the shared host plant. Sci. Reports 8, 3996. doi: 10.1038/s41598-018-22353-2

Pineda, A., and Marcos-García, M. A. (2008). Seasonal abundance of aphidophagous hoverflies (Diptera: Syrphidae) and their population levels in and outside mediterranean sweet pepper greenhouses. Ann. Entomol. Soc. Am. 101, 384-391. doi: 10.1603/0013-8746(2008)101[384:SAOAHD]2.0.CO;2

Pineda, A., Morales, I., Marcos-García, M. A., and Fereres, A. (2007). Oviposition avoidance of parasitized aphid colonies by the syrphid predator Episyrphus balteatus mediated by different cues. Biol. Control. 42, 274-280. doi: 10.1016/j.biocontrol.2007.05.017

Pineda, A., Soler, R., Pastor, V., Li, Y., and Dicke, M. (2017). Plant-mediated species networks: the modulating role of herbivore density. Ecol. Entomol. 42, 449-457. doi: 10.1111/een.12404

Ponzio, C., Cascone, P., Cusumano, A., Weldegergis, N. E. F., Guerrieri, E., Dicke, M., et al. (2016). Volatile-mediated foraging behaviour of three parasitoid species under conditions of dual insect herbivore attack. Anim. Behav. 111, 197-206. doi: 10.1016/j.anbehav.2015.10.024

Ponzio, C., Gols, R., Weldedergis, B. T., and Dicke, M. (2014). Caterpillar-induced plant volatiles remain a reliable signal for foraging wasps during dual attack with a plant pathogen or non-host insect herbivore. Plant Cell Environ. 37, 1924-1935. doi: 10.1371/journal.pone.0011063

Shiojiri, K., Takabayashi, J., Yano, S., and Takafuji, A. (2002). Oviposition preferences of herbivores are affected by tri-trophic interaction webs. Ecol Lett. 5, 186-192. doi: 10.1046/j.1461-0248.2002. 00292.x
Shipp, J., Hao, X., Papadopoulos, A., and Binns, M. (1998). Impact of Western Flower Thrips (Thysanoptera: Thripidae) on growth, photosynthesis and productivity of greenhouse sweet pepper. Sci. Hortic. 78, 87-102. doi: 10.1016/S0304-4238(97)00130-1

Stam, J. M., Chrétien, L., Dicke, M., and Poelman, E. H. (2017). Response of Brassica oleracea to temporal variation in attack by two herbivores affects preference and performance of a third herbivore. Ecol. Entomol. 42, 803-815. doi: 10.1111/een.12455

Stam, J. M., Kroes, A., Li, Y., Gols, R., van Loon, J. J. A., Poelman, E. H., et al. (2014). Plant interactions with multiple insect herbivores: from community to genes. Annu. Rev. Plant Biol. 65, 689-713. doi: 10.1146/annurev-arplant-050213-035937

Stubbs, A. E., and Falck, S. J. (1983). British Hoverflies: An Illustrated Identification Guide. British Entomological and Natural History Society.

Vaello, T., Casas, J. L., Pineda, A., de Alfonso, I., and Marcos-García, M. A. (2017). Olfactory response of the Predatory Bug Orius laevigatus (Hemiptera: Anthocoridae) to the aggregation pheromone of its prey, Frankliniella occidentalis (Thysanoptera: Thripidae). Environ. Entomol. 46, 1115-1119. doi: 10.1093/ee/nvx141

Vaello, T., Sarde, S. J., Marcos-García, M. Á., De Boer, J. G., and Pineda, A. (2018). Modulation of plant-mediated interactions between herbivores of different feeding guilds : effects of parasitism and belowground interactions. Sci. Reports 8:14424. doi: 10.1038/s41598-018-32131-9

van Maanen, R., Broufas, G., Oveja, M. F., Sabelis, M. W., and Janssen, A. (2012). Intraguild predation among plant pests: western flower thrips larvae feed on whitefly crawlers. BioControl 57, 533-539. doi: 10.1007/s10526-011-9433-z

Verheggen, F. J., Arnaud, L., Bartram, S., Gohy, M., and Haubruge, E. (2008). Aphid and plant volatiles induce oviposition in an aphidophagous hoverfly. J. Chem. Ecol. 34.,301-307. doi: 10.1007/s10886-008-9434-2

Welter, S. C., Rosenheim, J. A., Johnson, M. W., Mau, R. F. L., and GusukumaMinuto, L. R. (1990). Effects of Thrips-Palmi and Western Flower Thrips (Thysanoptera, Thripidae) on the yield, growth, and carbon allocation pattern in cucumbers. J. Econ. Entomol. 83, 2092-2101. doi: 10.1093/jee/83.5.2092

Zada, A., and Harel, M. (2004). Enzymatic transesterification of racemic lavandulol: preparation of the two enantiomeric alcohols and of the two enantiomers of lavandulyl senecioate. Tetrahedr. Asymm. 15, 2339-2343. doi: 10.1016/j.tetasy.2004.06.015

Zhang, P. J., Zheng, S. J., van Loon, J. J. A., Boland, W., David, A., Mumm, R., et al. (2009). Whiteflies interfere with indirect plant defense against spider mites in Lima bean. Proc. Natl. Acad. Sci. U. S. A. 106, 21202-21207. doi: $10.1073 /$ pnas.0907890106

Conflict of Interest Statement: The authors declare that the research was conducted in the absence of any commercial or financial relationships that could be construed as a potential conflict of interest.

Copyright (c) 2019 Vaello, Pineda and Marcos-García. This is an open-access article distributed under the terms of the Creative Commons Attribution License (CC BY). The use, distribution or reproduction in other forums is permitted, provided the original author(s) and the copyright owner(s) are credited and that the original publication in this journal is cited, in accordance with accepted academic practice. No use, distribution or reproduction is permitted which does not comply with these terms. 